\title{
5 Steps to a Perfect Practice Website
}

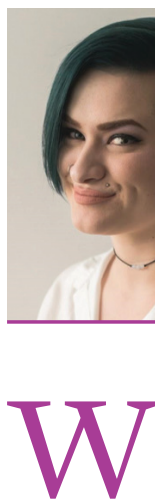

e live in a digital world, so a website is essential if you want your practice to get noticed. But it's not necessarily enough to have just a website; if you want to compete with the other practices in town (especially the big box stores), you need a great website.

Ideally, you'll hire an agency specializing in building high-converting websites, and that understands the eye care industry. Whether you're building a new website or updating your current one, these five steps could be enough to elevate your website to the next level.

\section{CONSIDER YOUR USER}

The most important thing to keep in mind when building or updating your practice website is user experience. User experience or UX should apply to almost every part of your website. For example, $53 \%$ of users will abandon a page if it doesn't load within three seconds. Users also don't read website content word for word; they skim it. So your website content should be broken into small chunks with headlines for easy scanning.

Keeping your user's information needs at the forefront is an excellent start.

\section{INTRODUCE YOURSELF}

Marketing4ECPs has built countless websites over the years, and we've noticed a fascinating trend. The page users visit most after the homepage is the "About Our Practice" page.

Potential patients want to know who you are and what you're about. Be sure to include your mission statement, core values, and short staff bios for your doctors and any other staff you'd like to highlight.

While you're there, make sure you mention any charities or community organizations your practice is involved with. $86 \%$ of consumers look for purpose-driven brands.

\section{SHOW THEM WHAT YOU'VE GOT}

You will never get new dry eye clients if consumers in your area don't know you offer specialized dry eye treatments. Your website needs to highlight all the services you offer, or at least all the main services you offer. Also consider that patients are typing in symptoms as they don't necessarily know that they have dry eye, so having symptom-based keywords on the dry eye page is key to showing up in a search.

Ideally, each service should have its own dedicated webpage. That will give you the best results from an search engine optimization (SEO) standpoint. But at the very least, you should include a list of all your services somewhere on your website. 


\section{UPDATE YOUR BRAND}

Websites that look nice and modern just perform well. Investing in your website's design shows users that you are willing and able to change with the times. A website from 2012 might serve some basic purposes, but it could give consumers the wrong impression.

You don't necessarily need to come up with an entirely new logo or change your brand colours. But you should make sure the imagery on your website is recent and inclusive. Use clean, legible fonts, try layouts that are easy to browse through, and incorporate colours and textures from your practice's interior if you can. Did we mention design rules when it comes to why a consumer chooses an Optometry website?

\section{ANSWER THE IMPORTANT QUESTIONS}

When people perform a Google search, they're virtually always asking a question. Which optometry practices are closest to me? Why are my eyes dry? How often do I need an eye exam?

One of the best things your website can do is answer those questions.

Your service pages are a good place to answer questions. Think about the questions your clients ask you most, then create a Frequently Asked Questions (FAQ) section and populate it with those questions (and more importantly, answers).

Some questions are a little too specific or niche to make sense on a service page. Blogs are a great way to answer some of the more complex questions, like when can a child start wearing contact lenses or which type of laser refractive surgery is right for me?

Giving users access to your expertise builds trust, so even if the user doesn't need to book an appointment today, they're more likely to think of you when they do.

YOUR WEBSITE IS A LIVING, BREATHING THING

No matter what, it's important to remember that as technology, medical science, and user behaviours change, website best practices will change too. It's best to continue optimizing and refreshing your website to get the best possible performance out of it.

If you can stay on top of ever-changing digital trends, you'll have a very good shot at staying at the top of your market, too. 